\title{
Non-Deceptive Counterfeiting Purchase Behavior: Antecedents Of Attitudes And Purchase Intentions
}

\author{
Mateja Kos Koklic, University of Ljubljana, Slovenia
}

\begin{abstract}
This study offers insights into factors underlying consumers' intentions to purchase counterfeit products. Based on existing literature in the field, we posit that intention to buy is influenced by consumers' attitudes, moral intensity and perceived risk. In addition, we hypothesize that attitudes are determined by moral intensity and perceived risk. The hypotheses are tested with data gathered from a random sample of adult consumers using structural equations modeling. Implications of different patterns of results identified are also discussed.
\end{abstract}

Keywords: non-deceptive counterfeiting; consumer behavior; intention to buy a fake product

\section{INTRODUCTION}

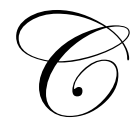

ounterfeiting has existed for a long time and is now considered as a serious economic, social and political problem (Veloutsou and Bian, 2008). OECD (2008) estimates that counterfeit and pirated goods could amount up to USD 250 billion in 2007. Consequently, there has been a long tradition of academic and industry led-research on the supply and the demand side of counterfeiting. However, there is a general absence of agreement in the literature with respect to the scope and magnitude of this problem, its actual social and economic impacts, and the effectiveness of anti-counterfeiting measures (BASCAP, 2008; Eisend and SchuchertGueler, 2006; OECD, 2008). On the other hand, researchers and analysts consent that the phenomenon is global in nature and that an in-depth understanding of the factors driving counterfeiting activities are a pre-requisite for national, industry or policy-driven actions.

This study focuses on the demand side of counterfeiting, examining factors underlying the purchase of nondeceptive counterfeit products. Unlike deceptive counterfeiting where consumers believe they have purchased a genuine product (when in fact it is a fake), the non-deceptive counterfeits refer to situations when consumers are fully aware that they are buying a knock-off at the time of purchase (Grossman and Shapiro, 1988). More specifically, the aim is to propose and test a model of the antecedents of consumer attitude and intention to buy counterfeit products. Namely, previous literature identified various issues to be addressed in future empirical studies to advance existing knowledge of the counterfeiting phenomenon, particularly the lack of consistent frameworks to guide empirical efforts and the dearth of focus on consumers outside the US and Asia (Eisend and Schuchert-Gueler, 2006; Veloutsou and Bian, 2008; Wilcox et al., 2009). According to Staake et al. (2009), our knowledge of the mechanisms and structure of the illicit market is still rather limited. Revealing insights into the determinants of counterfeit purchase behavior is critical if efficacious public policy strategies are to be developed. Along with the established behavior-related constructs, that is, a person's attitudes and intentions to perform certain behavior, one of the key constructs, identified in consumer behavior is perceived risk. Despite its prominent role, it has not been sufficiently examined in the counterfeiting context (Veloutsou and Bian, 2008). On the other hand, an under researched construct in the counterfeiting literature, but better explored in the piracy and ethics literature, is moral intensity. Along these lines, Loe et al. (2000) also proposed to conduct more research on this variable.

These issues, along with the calls for examinations of existing consumer behavior models in different and novel cultural settings prompted us to design a study with the central premise that perceived risk and moral intensity 
act as antecedents of consumer attitudes and intention to buy counterfeit products. We first develop a theory based conceptual model and then conduct a quantitative research study. Next, we apply path analyses to test the system of structural relationships. Finally, we discuss the implications of the findings and provide venues for further research.

\section{THEORETICAL FRAMEWORK}

The most common theoretical underpinnings for the studies on ethical behavior in a marketing context rely either on (1) the models of attitude-behavior relations, such as the Theory of Reasoned Action (TRA) (e.g., Shoham et al., 2008) and the Theory of Planned Behavior (TPB) (e.g., de Matos et al., 2007) or (2) the theories of ethical decision making, such as Jones' issue-contingent model (e.g., Tan, 2002), Hunt and Vitell's model of ethical decision making (e.g., Shang et al., 2008), or the Ferrell and Gresham's (1985) contingency framework (e.g. Simpson, et al., 1994). In addition, expected utility theory or deterrence theory (e.g. Hennig-Thurau et al., 2007), equity theory (e.g. Glass and Wood, 1996), or the exchange theory (e.g. Coyle et al., 2009) have also been applied in the studies on counterfeiting and piracy.

The basic premise of the models of attitude-behavior relations is the interplay between attitudes, intentions and actual behavior (Bentler and Speckart, 1979). The basic assumption of these models is that attitudes shape intentions and intentions shape an individual's behavior. This framework, either as TRA or TPB, has been applied to both, counterfeiting (e.g., Shoham et al., 2008) and piracy context (e.g., Goles et al. 2008). One valuable characteristic of this theory is its flexibility in allowing the inclusion of other theoretically relevant variables (Ajzen, 1991). Yet, overall attitudes alone are usually poor predictors of behaviors (e.g. De Pelsmacker and Janssens, 2007). Several studies in the counterfeiting and piracy literature found constructs other than attitudes tend to have a stronger power in predicting behavioral intentions (e.g., by Chang, 1998). Shaw et al. (2005) conclude that a substantial amount of variance in buying behavior remains unexplained by traditional models based on TRA and that other relevant variables should be included.

An alternative stream in the counterfeiting and piracy research relies on the theories of ethical decision making, since counterfeiting and piracy are, depending on the situation, considered as illegal and/or unethical practices (Simpson et al., 1994). Rest (1979) suggested a four-component model which stipulates that an individual must (1) recognize the moral issue, (2) make a moral judgment, (3) establish moral intent, and (4) implement moral actions during the ethical decision-making and behavior process. Jones (1991) used these foundations to propose the issue-contingent model, which held that ethical decisions are contingent on the characteristics of the issues at stake. Rest's model has been extended with the concept of moral intensity with the role to capture the extent of issuerelated moral imperative in a situation (Jones, 1991, p. 372). The basic premise of ethical decision making models is that a person must be able to recognize a moral issue, either in case of purchasing a counterfeit product or pirating digital content. Yet, some studies suggest that many individuals do not perceive software piracy as a moral or ethical issue (e.g., Solomon and O'Brien, 1990). In this respect, the ethical research stream offers an insightful starting point for identifying the relevant variables of buying counterfeit goods behavior, such as moral intensity.

\section{RESEARCH MODEL}

Against this background, a model is proposed consisting of consumer attitudes toward purchasing counterfeit leisure goods and intention to buy such goods. Attitude is shown to be significantly correlated with counterfeiting behavior (Bian and Veloutsou, 2007, de Matos et al., 2007), and one's intention is thought to capture the motivational factors that affect behavior (Cronan and Al-Rafee, 2008). The relationship between these two constructs is further extended with the concepts of (1) moral intensity and (2) perceived risk. Moral intensity and perceived risk can be regarded as two sets of perceived consequences of counterfeit purchases. Moral intensity elicits the expected consequences for the society at large and is defined as the extent of issue-related moral imperative in a situation of knowingly purchasing counterfeit products. By including the moral intensity construct into the TRA model, an important component of the issue-contingent model for the ethical decision making is integrated into the proposed model. Perceived risk assesses the perceived consequences for the individual who buys counterfeit products, and it involves the perceived negative consequences of knowingly purchasing counterfeit products. It has been recognized as a critical factor influencing ethical decision making (Tan, 2002). The model is depicted in Figure 1. 
Figure 1. A Conceptual Model

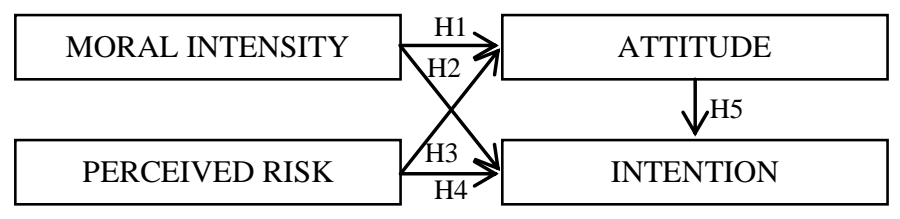

The moral intensity concept has been previously investigated mostly in the business context, suggesting its significant effects on components of the ethical decision making, e.g., moral intent and moral behavior (e.g. Carlson et al., 2002; Sighapakdi et al., 1996). Based on the inherent properties of moral judgment, it can be noted that the attitude is the closest construct. These two constructs have been previously used to explain intention/behavior, both are judgments or evaluations about a particular behavior and both lead to intention, which in turn results in behavioral outcomes (Al-Rafee and Cronan, 2006). On the other hand, Chiou et al. (2005) provided empirical evidence for the negative impact of moral intensity on general positive attitudes of unauthorized music download/duplication. Tan (2002) also hypothesized and partly provided evidence for the negative impact of moral intensity on the intention to purchase pirated software. Based on these studies, we hypothesize:

H1: Moral intensity positively influences unfavorable Attitude toward purchasing CF products.

H2: Moral intensity negatively influences Intention to buy CF products.

Perceived risk is another independent variable hypothesized to affect consumer's attitude and intentions. Several studies have established evidence that perceived risk decreases consumer's intention to buy counterfeit products or pirate. For example, the study by de Matos et al. (2007) revealed that perceived risk was the most important variable to predict consumer attitude toward counterfeits. In addition, Chiou et al. (2005) found that perceived prosecution risk negatively influences the attitude of unauthorized duplication/download and the attitude of pirated music product purchasing. On the other hand, perceived risk has also been documented as diminishing consumer's favorable attitude toward buying counterfeit product or pirating. Albers-Miller (1999) confirmed that perceived risk decreases the willingness to buy counterfeit color TVs. Similarly, Bian and Moutinho (2008) showed that the greater the perceived risk, the lower is the likelihood of consumers' consideration of counterfeit branded products. In the piracy context, perceived risk has also been shown to reduce the intention to pirate (e.g. Sinha and Mandel, 2008; Tan, 2002). Therefore, we propose:

H3: $\quad$ Perceived Risk positively influences unfavorable Attitude toward purchasing CF products.

H4: $\quad$ Perceived Risk negatively influences the Intention to buy CF products.

The link attitude-behavioral intention has been extensively studied in the marketing literature. Consequently, there is a bulk of evidence in favor of positive relationship between attitudes and behavioral intentions. In the counterfeiting context, quite many authors provided support for this relationship, including Ang et al. (2001), de Matos et al. (2007), and Wilcox et al. (2009). Similarly, the positive influence of attitudes on intention has also been confirmed in the digital piracy context (e.g., Cronan and Al-Raffee, 2008), music piracy context (e.g., Chiou et al., 2005), and software piracy (e.g., Goles et al., 2008). Hence, we propose the following research hypothesis:

H5: Consumer's unfavorable Attitude toward purchasing CF products negatively affects Intention to buy CF products.

\section{LITERATURE REVIEW}

According to the report issued by OECD (2008), the scope and magnitude of counterfeiting has been broadening, and consequently, this area has increasingly attracted the academic research interest. Staake et al. (2009) note that very few publications are dedicated to the supply side and the largest portion of research is dealing with the demand side of the market with counterfeit goods. One of the main reasons for research on counterfeiting is its adverse effect on industries producing genuine products. Following the significant impact of counterfeiting on 
genuine products, several recent studies have delved into this topic. For example, Wilcox et al. (2009) have explored social motivations behind purchasing counterfeit luxury brands, while Commuri (2009) examined strategies adopted by consumers when faced with the prospect of their favorite brand being counterfeited. On the other hand, Han et al. (2010) addressed the need for status suggesting one group of people chooses to buy counterfeits to meet this need.

In examining the existing literature on consumer counterfeiting and piracy, several research streams can be identified: (1) looking at the demographic characteristics related to counterfeiting or piracy (e.g. Ergin, 2010; Swami et al., 2009), (2) identifying ethical/moral issues underlying consumers' decisions to purchase counterfeit goods or to illegally copy software (e.g. Jones, 1991; Simpson et al. 1994), and (3) examining situational and individual normative variables (e.g. Eining and Christensen, 1991; Furnham and Valgeirsson, 2007; Haque et al., 2009). The counterfeiting studies mostly tackle consumer awareness, attitudes and purchase intentions, purchase and product use, and demographic characteristics (Eisend and Shuchert-Gueller, 2006; Staake et al., 2009). With respect to consumer awareness, deceptive and non-deceptive counterfeits are generally viewed as two distinct concepts, while Bosworth (2006) has suggested having a spectrum of deception that runs from "super-deceptive" to completely nondeceptive. Depending on whether a consumer is intentionally buying a counterfeit product, his/her behavior is shaped differently, resulting in different implications and recommendations for stakeholders involved in the process.

Looking into the research on models of attitude-behavior relations in the context of consumers' nondeceptive counterfeit purchases, two focal constructs are an individual's attitude and his/her intention. As suggested in the Theoretical Framework section, a number of studies employed these models, e.g., Peace et al. (2003), de Matos et al. (2007), Kim and Karpova (2010). Another aspect on this framework was presented by Eisend and Shuchert-Gueller (2006), who, based on the existing studies, classified the determinants of attitudes towards counterfeiting and decision and intention to purchase counterfeit products into the following categories: productrelated variables (e.g., Bian and Moutinho, 2008), social and cultural context variables (e.g., Lai and Zaichkowsky, 1999), person-related variables (demographics and psychographic variables) (e.g., Furnham and Valgeirsson, 2007), and purchase situation and mood (e.g., Gentry et al., 2001).

Within the group of person-related variables, a number of various factors have been examined, for example: demographic variables (e.g. Bloch et al., 1993; Bian and Veloutsou, 2008), willingness to take risks (Eisend and Shuchert-Gueller, 2006), beliefs about counterfeits (Gentry et al., 2006), ethics/morals-related variables (e.g., Ha and Lennon, 2006), risk perception (de Matos et al., 2007; Bian and Moutinho, 2008). Of particular relevance to this study are variables related to ethics/morals and risk perception. Namely, in order to account for the moral perspective, the proposed conceptual model also includes one moral component: moral intensity. It has been previously studied in a relatively few counterfeiting/ piracy settings (e.g. Chiou and Lee, 2005; Tan, 2002), but has been examined in a number of other ethical decision-making situations (e.g. Glover et al., 1997; Franke et al., 1997). Furthermore, one of the major explanatory variables of consumer behavior in many product categories has been perceived risk (Mitchell, 1999). Perceived risk arises in situations where consumers are uncertain about the outcome of a choice and are concerned about the consequences of a poor or wrong decision (Havlena and DeSarbo, 1991). Consequently, several studies in the areas of consumer counterfeit purchase included this variable as an important explanatory construct. For example, Veloutsou and Bian (2008) investigated the relationships between different dimensions of perceived risk in the context of non-deceptive counterfeit brands, Albers-Miller (1999) showed that perceived risk predicts the decision to purchase illicit goods for some of the groups, Bian and Moutinho (2008) suggested that risk influences the likelihood of purchase of counterfeit branded product, while de Matos et al. (2007) found that perceived risk significantly shapes an individual's attitude toward counterfeits.

\section{RESEARCH METHODOLOGY}

\section{Research Method}

The aim of the study, which was to propose and test a conceptual model based on the existing theoretical and empirical knowledge regarding counterfeiting purchase behavior, prompted us to utilize quantitative research method. For this study mail questionnaires were selected. Compared to other quantitative techniques, the population for the sampling needs to be identified in advance. This implies that a valid list of potential respondents is needed. The following advantages encouraged us to use mail questionnaire: presenting questions is easier; asking batteries of 
similar questions is possible; the respondent doesn't have to share answers with an interviewer; cost is relatively low; mail procedures can be accomplished with minimal staff and facilities; they provide access to widely dispersed samples; respondents have time to give thoughtful answers (Kumar et al., 1999).

\section{Procedure and Data Collection}

Hypotheses were tested by collecting data via self-administered mail survey which was sent to an initial sample of 10,000 consumers in Slovenia, representative of the population in the country based on gender, age, type of settlement and region. This country offers an appealing site for research on counterfeiting for the following reasons: a) general absence of research investigating consumer ethical issues in transitional economies (Al-Khatib et al., 2004); b) purchasing of counterfeit goods continues to represent a global rather than regional problem (e.g., Wilcox et al. 2009). While the total number of the returned questionnaires was 1523 , several questionnaires were eliminated due to missing or incomplete data. Hence, $79.5 \%$ of the returned questionnaires (1211 questionnaires) were included for the analysis in the present study. Our sample consisted of more female than male respondents (56.1\% females) with an average age of 42 years (SD of 16.5 ). The majority of the sample (73.9\%) attained college education, and just over half of the sample (52.4\%) was employed, either on a part-time or full-time basis.

\section{Measures}

Three constructs, perceived Risk, (unfavorable) Attitude and Intention to buy CF products were measured on 5-point Likert type scales ranging from 1 (Strongly Disagree) to 5 (Strongly Agree); the construct of Moral intensity was measured on a 5-point semantic differential scale. Construct measures were derived from existing literature, but carefully adapted to the cultural context with additional testing of reliability in this study. We examined measures used in studies focusing either on counterfeiting or piracy; both present forms of illicit trade (Staake et al., 2009). The measure of CF purchase Intention was assessed using a three-item scale developed by Taylor and Todd (1995) which has been applied in the recent study on softlifting (Goles et al., 2008). To capture the Attitude toward purchasing CF products, items relating to the overall favorableness of pirating digital media based on Cronan and Al-Rafee, (2008) and items referring to the evaluation of counterfeit products by de Matos et al. (2007) were used. Moral intensity scale items were adapted from Singhapakdi et al. (1996) and McMahon and Harvey (2006). Items for perceived Risk were derived from Hennig-Thurau's et al. (2007) scale.

\section{Analyses}

After data collection, an exploratory factor analysis (EFA) was used to test for constructs' unidimensionality. In addition, descriptive statistics with items' mean values and inter-item correlations were obtained. Then, the two-step analysis procedure suggested by Anderson and Gerbing (1988) was followed. First, a confirmatory analysis with LISREL was used to check the validity and reliability of the measurement items. In terms of validity, convergent and discriminant validity were evaluated, while reliability was tapped by checking internal consistency coefficient (Cronbach's alpha), composite reliability and average variance extracted as suggested in the measurement literature (e.g. Fornell and Larcker, 1981). The final measurement model was modified by taking the theoretical limitations, modification diagnostics, and validity of indicators into account. In the second step, structural equation analysis was performed to test the hypotheses empirically.

\section{RESEARCH RESULTS}

First, an exploratory factor analysis was employed to test for constructs' uni-dimensionality. Using Principal Axis Factoring as the extraction method, four factors were extracted: moral intensity, risk, attitude and intention. The loadings for the moral intensity items ranged from 0.62 to 0.82 , the risk item loadings ranged from 0.57 to 0.80 , similarly, the attitude item loadings were within the range 0.55 to 0.72 , while the items measuring intention loaded within the range 0.38 to 0.85 . All other cross-loadings exhibited values lower than 0.30 . These results indicate that the items group into four factors and unidimensionality for each of the factors was obtained.

The scale items exhibited rather low means varying from 2.00 to 3.63 on a scale from 1 to 5 . The means of the three moral intensity items ranged between 2.61 and 3.02. The four perceived risk items presented means 
varying from 2.00 to 2.37 , while the means for the attitude items were slightly above average, ranging from 3.03 to 3.23. The intention to buy items displayed mean values between 3.23 and 3.63. Next to mean values, the inter-item correlations were also checked for each set of items separately. These values, as well as Kendall's tau-b and Spearman's rho were all statistically significant at a two-sided test using level of significance 0.01 . In case of moral intensity, the correlations between its items ranged from 0.46 to 0.58 (Kendall's tau-b: $0.44-0.54$; Spearman's rho: $0.49-0.50$ ). The correlations between items measuring perceived risk varied from 0.44 to 0.73 (Kendall's tau-b: 0.44-0.684; Spearman's rho: 0.45-0.72), attitude items correlated in the range of values 0.50 to 0.63 (Kendall's taub: $0.45-0.57$; Spearman's rho: $0.50-0.63$ ), and the intention items displayed correlations between 0.35 and 0.73 (Kendall's tau-b: 0.36-0.67; Spearman's rho: 0.41-0.74). The descriptive statistics and inter-item correlations are displayed in Table 1.

Table 1. Descriptive statistics and inter-item correlations

\begin{tabular}{|c|c|c|c|c|c|c|c|c|c|c|c|c|c|c|c|}
\hline & Mean & Std. Dev. & mi1 & $\mathrm{mi} 2$ & $\mathrm{mi} 3$ & risk1 & risk2 & risk3 & risk4 & att1 & att2 & att3 & int1 & int2 & int3 \\
\hline mil & 2,31 & 0,68 & 1,00 & 0,57 & 0,46 & 0,17 & 0,25 & 0,19 & 0,22 & $-0,31$ & $-0,36$ & $-0,28$ & $-0,25$ & $-0,12$ & $-0,28$ \\
\hline $\mathrm{mi} 2$ & 3,06 & 1,11 & 0,57 & 1,00 & 0,58 & 0,16 & 0,26 & 0,23 & 0,20 & $-0,29$ & $-0,36$ & $-0,29$ & $-0,22$ & $-0,08$ & $-0,27$ \\
\hline $\mathrm{mi} 3$ & 3,02 & 1,09 & 0,46 & 0,58 & 1,00 & 0,14 & 0,18 & 0,14 & 0,13 & $-0,19$ & $-0,25$ & $-0,25$ & $-0,14$ & $-0,04$ & $-0,16$ \\
\hline risk1 & 2,00 & 0,77 & 0,17 & 0,16 & 0,14 & 1,00 & 0,50 & 0,44 & 0,46 & $-0,23$ & $-0,23$ & $-0,19$ & $-0,20$ & $-0,19$ & $-0,19$ \\
\hline risk2 & 2,37 & 0,89 & 0,25 & 0,26 & 0,18 & 0,50 & 1,00 & 0,73 & 0,50 & $-0,33$ & $-0,35$ & $-0,26$ & $-0,25$ & $-0,17$ & $-0,29$ \\
\hline risk3 & 2,21 & 0,87 & 0,19 & 0,23 & 0,14 & 0,44 & 0,73 & 1,00 & 0,53 & $-0,28$ & $-0,32$ & $-0,26$ & $-0,20$ & $-0,14$ & $-0,21$ \\
\hline risk4 & 2,04 & 0,79 & 0,22 & 0,20 & 0,13 & 0,46 & 0,50 & 0,53 & 1,00 & $-0,29$ & $-0,33$ & $-0,24$ & $-0,25$ & $-0,17$ & $-0,25$ \\
\hline att1 & 3,12 & 1,05 & $-0,31$ & $-0,29$ & $-0,19$ & $-0,23$ & $-0,33$ & $-0,28$ & $-0,29$ & 1,00 & 0,63 & 0,50 & 0,35 & 0,29 & 0,40 \\
\hline att2 & 3,03 & 1,07 & $-0,36$ & $-0,36$ & $-0,25$ & $-0,23$ & $-0,35$ & $-0,32$ & $-0,33$ & 0,63 & 1,00 & 0,51 & 0,37 & 0,25 & 0,45 \\
\hline att3 & 3,23 & 1,04 & $-0,28$ & $-0,29$ & $-0,25$ & $-0,19$ & $-0,26$ & $-0,26$ & $-0,24$ & 0,50 & 0,51 & 1,00 & 0,27 & 0,20 & 0,29 \\
\hline int 1 & 3,63 & 1,07 & $-0,25$ & $-0,22$ & $-0,14$ & $-0,20$ & $-0,25$ & $-0,20$ & $-0,25$ & 0,35 & 0,37 & 0,27 & 1,00 & 0,38 & 0,73 \\
\hline int2 & 3,47 & 1,22 & $-0,12$ & $-0,08$ & $-0,04$ & $-0,19$ & $-0,17$ & $-0,14$ & $-0,17$ & 0,29 & 0,25 & 0,20 & 0,38 & 1,00 & 0,35 \\
\hline int3 & 3,23 & 1,25 & $-0,28$ & $-0,27$ & $-0,16$ & $-0,19$ & $-0,29$ & $-0,21$ & $-0,25$ & 0,40 & 0,45 & 0,29 & 0,73 & 0,35 & 1,00 \\
\hline
\end{tabular}

* mi = Moral Intensity item; risk = perceived Risk item; att = Attitude item; int = Intention item

The chi-square test and fit indices indicated that the measurement model had a good fit. All the factor loadings and error variances were statistically significant (at $\mathrm{p}<0.05)$, which confirms the convergent validity of the selected indicators. To assess reliability of the constructs, three test indices were used: Cronbach's alpha, composite reliability and average variance extracted. First, internal consistency was assessed by calculating Cronbach's alpha for each construct. For the Moral intensity construct, the alpha value was 0.76, for perceived Risk 0.82, for Attitude 0.78 and for behavioral Intention 0.73. All the values are superior to 0.60 and 0.70 , which Hair et al. (1998) suggest to be the lower limit of acceptability. The scales also exhibited acceptable composite reliability (CR) and average variance extracted (AVE), the former ranging from 0.77 to 0.73 and the latter varying from 0.53 to 0.55 , with the cut-off values 0.70 and 0.50 , respectively. The discriminant validity was checked by constraining the covariance in any set of two constructs (Anderson and Gerbing, 1988) and this significantly deteriorated the model fit. It may be concluded that the model has acceptable validity and reliability of the measures.

Next, the structural model was evaluated in order to test the hypotheses. The model displays good fit indices $\left(\chi^{2}=180\right.$, d.f. $=58, p=0.00 ; \mathrm{GFI}=0.98 ; \mathrm{NFI}=0.97$; TLI $=0.97$; CFI $=0.98$, RMSEA $\left.=0.04\right)$. The results of the hypotheses testing are summarized in Table 2. While hypotheses H1, H3, H4 and H5 are well supported, no support is found for the impact of Moral intensity on the Intention (H2).

Table 2. Hypothesis Testing and Results

\begin{tabular}{|c|c|c|c|c|c|}
\hline & \multicolumn{3}{|c|}{ Hypothesis } & Path Coefficients $(\boldsymbol{t}$-Value*) & Hypothesis \\
\hline H1+ & Moral Intensity & $\rightarrow$ & Attitude & $0.39(11.1)$ & Supported \\
\hline H2- & Moral Intensity & $\rightarrow$ & Intention & $-0.06(-1.7)$ & Not supported \\
\hline H3+ & Risk & $\rightarrow$ & Attitude & $0.36(10.7)$ & Supported \\
\hline H4- & Risk & $\rightarrow$ & Intention & $-0.08(-2.3)$ & Supported \\
\hline H5- & Attitude & $\rightarrow$ & Intention & $-0.50(-11.2)$ & Supported \\
\hline
\end{tabular}

* Significant at $\mathrm{p} \leq 0.05$ if $|\mathrm{t}| \geq 1.96$. 


\section{DISCUSSION}

In reviewing the consumer behavior literature and recent empirical studies, we identified two variables (Moral intensity and Risk) that influence consumer attitude toward purchasing counterfeits and three variables (Attitude, Moral intensity and Risk) that affect consumer Intention to buy CF products. Our empirical research findings suggest that Moral intensity significantly influences unfavorable Attitude toward purchasing CF products, which is in line with hypothesis H1. On the other hand, the anticipated negative impact of Moral intensity on Intention was not confirmed; therefore, $\mathrm{H} 2$ cannot be supported. Further, our empirical results lend support to $\mathrm{H} 3$ and H4, namely, perceived Risk influences unfavorable Attitude, as well as Intention to buy CF products. The last hypothesis, $\mathrm{H} 5$, is also supported by the data and implies that unfavorable Attitude toward purchasing CF products negatively affects consumer's Intention to purchase such products.

In this study, empirical supported was found for two determinants of unfavorable Attitude toward purchasing counterfeits: Moral intensity and perceived Risk. To the best of our knowledge, the previous literature on counterfeiting has not explicitly included the two determinants in a single study. On the other hand, Chiou et al. (2005) empirically validated the negative influence of moral intensity and perceived prosecution risk on the attitude of music piracy in the piracy context. It can also be noted that few studies focused on moral intensity as attitude's antecedent in the counterfeiting context, while perceived risk and attitude were relatively well covered (e.g., Maldonado, 2005; de Matos et al., 2007). Our findings indicate that Moral intensity and perceived Risk explain almost the same amount of variance in Attitude. This means not only do people form their attitudes based on how they perceive consequences of purchasing counterfeits for themselves, but also based on consequences for the society as a whole.

On the other hand, the Intention to buy CF products is influenced by consumers' unfavorable Attitude toward counterfeiting and their perceptions of Risk involved. As hypothesized, negative predisposition toward purchasing counterfeit products (Attitude) reduces consumer's Intention to engage in knowingly buying a CF product. These findings are in line with previous empirical work. Attitude is found to be one of the most consistent predictors of purchasing, including in the counterfeiting context (e.g., Ang et al., 2001; de Matos et al., 2007; Kwong et al., 2003; Phau and Teah, 2009; Wilcox et al., 2009). Our finding related to perceived Risk as a significant determinant of the Intention is also consistent with other studies (e.g., Albers-Miller, 1999; Bian and Moutinho, 2008).

However, the hypothesized direct impact of Moral intensity on purchase Intention was not confirmed in this study. Although the literature on the relationship between moral intensity and intention is rather scarce, it still provides a relatively uniform evidence of a negative relationship, i.e. moral intensity reduces the intention to purchase counterfeit or pirated products (e.g., Chia and Mee, 2000; Tan, 2002). One possible explanation for this outcome might lie in the similarity of Moral intensity construct with the behavioral belief in TPB. Both are referring to the beliefs about consequences of engaging in a certain behavior, and according to TPB, the path from behavioral beliefs to behavioral intention is fully mediated by the attitude toward behavior (Ajzen, 1991).

This study aims to extend the existing knowledge about the demand side of the counterfeiting phenomenon. Several theoretical implications can be drawn from it. As discussed in the Theoretical framework section, the models of attitude-behavior relations allow flexible inclusion of various variables (Ajzen, 1991). We have demonstrated that not only attitude but also risk perception can be regarded as a significant determinant of behavioral intention. In addition, by including Moral intensity into the model, the ethical perspective on counterfeiting is tackled. In this way, we partly respond to the call of Loe et al. (2000) to more thoroughly integrate ethics issues in other areas of research. Also, there is a dearth of studies in the counterfeiting context with moral intensity as one of the components. Testing this construct along with perceived risk extends and refines the existing knowledge about attitude's and intention's determinants in case of purchasing counterfeit products.

As manufacturers, wholesalers, retailers and consumers have experienced increasing problems stemming from the proliferation of CF products in the market during the past few decades, the mitigation of these phenomena requires special attention. The range of activities extends from legislative efforts aimed at protecting IPR, promoting public awareness to encouraging new knowledge creation. When addressing the consumers as stakeholders in the 
process of counterfeit trade, it is important to understand that shaping demand for CF products along with consumer education constitutes a major leverage to confine illicit market activities (Staake et al., 2009). One of the ways to manage the demand side is to influence consumers' attitudes and intentions to purchase CF products. Based on the findings in this study, two powerful areas may prove effective in changing an individual's attitudes and intentions, i.e. the perception of consequences for oneself (i.e., perceived risk) and perception of consequences for others (i.e., moral intensity). We demonstrate that both significantly affect people's predisposition toward knowingly purchasing counterfeit products.

A compelling reason why knowledge of attitude's antecedents is so important is the fact that attitudes can be changed through persuasion and other means (Olson and Zanna, 1993). In this respect, three central motives that generate attitude change and resistance were identified in the literature: concerns with the self and with others and the rewards or punishments they can provide (Wood, 2000). Our suggestion is that perceived Risk and Moral intensity both touch upon concerns with the self and with others, which might lead to attitude change. Hence, inclusion of the two sets of potential consequences might increase the efficiency of the communication strategies employed by the rights holders and governments. Controlling for perceived Risk affects the Attitude and the purchase Intention. Therefore, our suggestion is to rely on perceived Risk as the main component of marketing communication messages intended to discourage consumption of counterfeits.

\section{CONCLUSION}

This research contributes to the existing body of knowledge in the field of counterfeiting. More specifically, two antecedents of unfavorable attitude toward purchasing counterfeit products and three antecedents of intention to buy counterfeits are suggested and empirically tested in this study. It has been shown that the underlying determinants of unfavorable attitude toward knowingly purchasing fake goods are on one hand perceived consequences for the society, and on the other hand, perceived consequences for oneself. Furthermore, this attitude along with perceived risk significantly shapes one's intention to engage in purchasing fake goods.

The results of this research should be viewed from the perspective of limitations inherent in this quantitative inquiry. First, the study focused on a limited range of counterfeit products, that is, leisure goods. Although counterfeits range from pharmaceutical products to aircraft parts, the narrower focus of this study needs to be taken into consideration. Second, the design of the study was cross-sectional, meaning that the concepts were measured at one point in time. Consequently, making inferences about concepts' dynamics is rather limited. Third, as the study measured behavioral intention as a proxy for behavior, it should be noted that there is a gap between an individual's intention to perform an act and his/her actual behavior due to other interfering factors. Fourth, although there are several compelling reasons for choosing Slovenia as the location to conduct this research, the specifics pertaining to this geographical location posit certain limitations in generalizing its conclusions.

This study provides tracks for further research directions. One would be to reexamine this model by gathering data in other geographical areas, taking into account influential cultural differences. The model could also be tested on products other than leisure goods to acquire knowledge about how generalizable the findings of this study are. As suggested in the previous section, different variables can be included into the attitude-behavior models in order to improve the amount of variance explained. For example, past behavior has been found to be the best predictor of future behavior (Conner and Armitrage, 1998) and could improve the explanatory power of the model. Similarly, some studies suggest that involvement should be considered as a vital determinant of consumer attitudes and intentions (de Matos et al., 2007). An interesting venue for further research would also be a longitudinal design of the study, enabling a more dynamic insight into the mechanisms of the non-deceptive counterfeit purchase process.

\section{AUTHOR INFORMATION}

Mateja Kos Koklic is an assistant professor of marketing at the Faculty of Economics, University of Ljubljana (FELU) in Slovenia, where she also received her $\mathrm{PhD}$ in 2007. Her research focuses on topics such as consumer behavior and consumer decision making, especially with respect to strategically important goods for consumers and perceived risk in different purchasing situations. The author has presented her findings at various conferences, such as ACR, EACR, and CROMAR, as well as published them in several journals. 


\section{REFERENCES}

1. Ajzen, I. (1991). The theory of planned behavior, Organizational Behavior and Human Decision Processes, 50, pp. 179-211.

2. Albers-Miller, N. D. (1999). Consumer Misbehavior: Why People buy Illicit Goods. Journal of Consumer Marketing, 16(3), pp. 273-287.

3. Al-Khatib, J. A., Robertson, C.J., \& Lascu, D.N. (2004). Post-Communist Consumer Ethics: The Case of Romania. Journal of Business Ethics, 54(1), pp. 81-95.

4. Al-Rafee, S. and Cronan, T. P. (2006). Digital Piracy: Factors that Influence Attitude toward Behavior. Journal of Business Ethics, 63(3), pp. 237-259.

5. Anderson, J. C. and Gerbing, D. W. (1988). Structural equation modeling in practice: A recommended two step approach. Psychological Bulletin, 103(3), pp. 411-423.

6. Ang, S. H., Cheng, P. S., Lim, A. A. C. and Tambyah, S. K. (2001). Spot the Difference: Consumer Responses Towards Counterfeits. Journal of Consumer Marketing, 18(3), pp. 219-235.

7. BASCAP, Business Action to Stop Counterfeiting and Piracy (2007). Global Survey on Counterfeiting and Piracy.

8. Bentler, P. M. \& Speckart, G. (1979). Models of Attitude-Behavior Relations. Psychological Review, 86(5), pp. $452-464$.

9. Bian X. \& Veloutsou C. (2007). Consumer's Attitudes towards Non-Deceptive Counterfeit Brands in the UK and China. Journal of Brand Management, 14(3), pp. 211-222.

10. Bian, X. and Moutinho, L. (2009). An investigation of determinants of counterfeit purchase consideration. Journal of Business Research, 62 (3), pp. 368-378.

11. Bloch, P. H., Bush, R.F., \& Campbell, L. (1993). Consumer 'Accomplices' in Product Counterfeiting. Journal of Consumer Marketing 10(4): pp. 27-36.

12. Carlson, D. S., Kacmar, K. M., \& Wadsworth, L. L. (2002). The impact of moral intensity dimensions on ethical decision making: Assessing the relevance of orientation. Journal of Managerial Issues, 14(1), pp. 15-30.

13. Chang, M. K. (1998). Predicting unethical behavior: A comparison of the Theory of reasoned action and the Theory of planned behavior. Journal of Business Ethics, 17(16), pp. 1825-1834.

14. Chia, A. and Mee, L. S. (2000). The Effects of Issue Characteristics on the Recognition of Moral Issues. Journal of Business Ethics, 27(3), pp. 255-269.

15. Chiou, J.-S., Huang, C., and Lee, H. (2005). The Antecedents of Music Piracy Attitudes and Intentions. Journal of Business Ethics, 57(2), pp. 161-174.

16. Commuri, S. (2009). The Impact of Counterfeiting on Genuine Item Consumers' Brand Relationships. Journal of Marketing, 73(3), 86-98.

17. Conner, M. \& Armitrage, C. (1998). Extending the Theory of Planned Behavior: A Review and Avenues for Further Research. Journal of Applied Social Psychology, 28(15), pp. 1429-1464.

18. Coyle, J. R., Gould, S. J., Gupta, P., \& Gupta, R. (2009). "To Buy or To Pirate": The Matrix of Music Consumers' Acquisition-Mode Decision-Making. Journal of Business Research, 62(10), pp. 1031-1037.

19. Cronan, T.-P. and Al-Rafee, S. (2008). Factors That Influence the Intention to Pirate Software and Media. Journal of Business Ethics, 78(4), pp. 527-545.

20. De Matos, C. A, Ituassu, C. T., and Rossi, C. A.V. (2007). Consumer attitudes toward counterfeits: A review and extension. Journal of Consumer Marketing, 24(1), pp. 36-47.

21. De Pelsmacker, P. \& Janssens, W. (2007). A Model for Fair Trade Buying Behaviour: The Role of Perceived Quantity and Quality of Information and of Product-specific Attitudes. Journal of Business Ethics, 75(4), pp. 361-380.

22. De Pelsmacker, P., Driesen, L. and Rayp, G. (2005). Do Consumers Care about Ethics? Willingness to Pay for Fair-Trade Coffee, Journal of Consumer Affairs, 39(2), pp. 363-385.

23. Eisend, M. and Schuchert-Güler, P. (2006). Explaining counterfeit purchases: A review and preview. Academy of Marketing Science Review, 6(12).

24. Ergin, E.A. (2010). The rise in the sales of counterfeit brands: The case of Turkish consumers. African Journal of Business Management, 4(10), pp. 2181-2186.

25. Ferrell, O. C. \& Gresham, L. G. (1985). A Contingency Framework for Understanding Ethical Decision Making in Marketing. Journal of Marketing, 49(3), pp. 87-96 
26. Fishbein, M. and Ajzen, I. (1975). Belief, Attitude, Intention, And Behavior: An Introduction To Theory And Research. Reading, Mass.: Addison-Wesley Pub. Co.

27. Fornell, C. \& Larcker, D. F. (1981). Structural equation models with unobservable variables and measurement error. Journal of Marketing Research, 18(1), pp. 39-50.

28. Franke, G. R., Deborah, F. C. \& Deborah, F. S. (1997). Gender differences in ethical perceptions of business practices: a social role theory perspective. Journal of Applied Psychology, 82(6), pp. 920-934.

29. Furnham, A. \& Valgeirsson, H. (2007). The effect of life values and materialism on buying counterfeit products. Journal of Socio-Economics, 36(5), pp. 677-685.

30. Gentry, J. W., Putrevu, S., Shultz, C., \& Commuri, S. (2001). How About Ralph Lauren? The Separation of Brand and Product in Counterfeit Culture. In Advances in Consumer Research, 28, Valdosta, GA: Association for Consumer Research, pp. 49-59.

31. Glass, R. S. \& Wood, W. A. (1996). Situational Determinants of Software Piracy: An Equity Theory Perspective. Journal of Business Ethics, 15(11), pp. 1189-1198.

32. Glover, S. H., Bumpus, M. A., Logan, J. E. \& Ciesla, J. R. (1997). Re-Examining the Influence of Individual Values on Ethical Decision Making. Journal of Business Ethics, 16(12/13), pp. 1319-1329.

33. Goles, T., Jayatilaka, B., George, B., Parsons, L., Chambers, V., Taylor D., and Brune, R. (2008). Softlifting: Exploring Determinants of Attitude. Journal of Business Ethics, 77(4), pp. 481-499.

34. Grossman, G. M. and Shapiro, C. (1988). Foreign counterfeiting of status goods. Quarterly Journal of Economics, 103(1), pp. 79-100.

35. Ha, S \& Lennon, S. (2006). Purchase intent for fashion counterfeit products: ethical ideologies, ethical judgments, and perceived risks. Clothing and Textiles Research Journal, 24(4), pp. 297-315.

36. Hair, J. F. Jr., Anderson, R. E., Tatham, R. L., \& Black, W. C. (1998). Multivariate Data Analysis (Fifth Edition). Upper Saddle River, New Jersey: Prentice Hall.

37. Han, Y. J., Nunes, J. \& Dreze, V. (2010). Signaling status with luxury goods: The role of brand prominence. Journal of Marketing 74(4), 15-30.

38. Haque, A., Khatibi, A., \& Rahman, S. (2009). Factors influencing buying behavior of piracy products and its impact to Malaysian market. International Review of Business Research Papers, 5(2), pp. 383-401.

39. Havlena, W. J. \& DeSarbo W. S. (1991). On the Measurement of Perceived Consumer Risk. Decision Sciences, 22(4), 1991, pp. 927-939.

40. Hennig-Thurau, T., Hennig, V., \& Sattler, H. (2007). Consumer File Sharing of Motion Pictures. Journal of Marketing, 71(4), pp. 1-18.

41. Jones, T. M. (1991). Ethical Decision Making by Individuals in Organizations: An Issue-Contingent Model. Academy of Management Review, 16(2), pp. 366-395.

42. Kim, H. \& Karpova E. (2010). Consumer attitudes toward fashion counterfeits: Application of the theory of planned behavior. Clothing and Textiles Research Journal, 28(2), pp. 79-94.

43. Kumar V., Aaker, D. A., \& Day, G. S. (1999). Essentials of Marketing Research. New York, NY: John Wiley \& Sons, Inc.

44. Kwong, K. K., Yau, O. H. M., Lee, J. S. Y., Sin, L. Y. M. and Tse, A. C. B. (2003). The effects of attitudinal and demographic factors on intention to buy pirated CDs: The case of Chinese consumers. Journal of Business Ethics, 47(3), pp. 223-235

45. Lai, K. K.-Y. \& Zaichkowsky, J. L. (1999). Brand Imitation: Do the Chinese Have Different Views?. Asia Pacific Journal of Management, 16(2), 179-192.

46. Loe, T. W., Ferrell, L. \& Mansfield, P. (2000). A Review of Empirical Studies Assessing Ethical Decision Making in Business. Journal of Business Ethics, 25(3), pp. 185-204.

47. Maldonado, C. (2005). Attitudes toward Counterfeit Products: An Ethical Perspective. Journal of Legal, Ethical and Regulatory Issues, 8(2), pp. 105-117.

48. McMahon, J. M. and Harvey, R. J. (2006). An analysis of the factor structure of Jones' moral intensity construct. Journal of Business Ethics, 64(4), pp. 381-404

49. Mitchell V-W. (1999). Consumer Perceived Risk: Conceptualisations and Models. European Journal of Marketing, 33(1/2), pp. 163-195.

50. OECD (2008). The economic impact of counterfeiting and piracy. Organisation for Economic Co-operation and Development.

51. Olson, J. \& Zanna, M. (1993). Attitudes and attitude change. Annual Review of Psychology, 44, pp. 117154. 
52. Peace, A., Galleta, D., and Thong, J. (2003). Software piracy in the workplace: a model and empirical test. Journal of Management Information Systems, 20(1), pp. 153-177.

53. Phau, I., and Teah, M. (2009). Devil wears (counterfeit) Prada: a study of antecedents and outcomes of attitudes towards counterfeits of luxury brands. Journal of Consumer Marketing, 26 (1), pp. 15-27.

54. Shang, R., Chen, Y., \& Chen, P. (2008). Ethical Decisions About Sharing Music Files in the P2P Environment. Journal of Business Ethics, 80(2), pp. 349-365.

55. Shaw, D., Grehan, E., Shiu, E., Hassan, L., and Thomson, J. (2005). An exploration of values in ethical consumer decision making, Journal of Consumer Behaviour, 4(3), pp. 185 - 200.

56. Shoham, A., Ruvio, A. and Davidow, M. (2008). (Un)ethical consumer behavior: Robin Hoods or plain hoods?. Journal of Consumer Marketing, 25(4), pp. 200-210.

57. Simpson, P. M., D. Banerjee and Simpson, C. L. (1994). Softlifting: A Model of Motivating Factors. Journal of Business Ethics, 13, pp. 431-438.

58. Singhapakdi, A., Vitell, S. J, and Kraft, K. L. (2008). Moral intensity and ethical decision-making of marketing professionals. Journal of Business Research, 36(3), pp. 245-255.

59. Sinha, R.K. \& Mandel, N. (2008). Preventing Digital Music Piracy: The Carrot or the Stick?. Journal of Marketing, 72(1), pp. 1-15.

60. Solomon, S. L. and O'Brien, J. A. (1990). The effect of demographic factors on attitudes toward software piracy. Journal of Computer Information Systems, 30(3), pp. 40-46.

61. Staake, T., Thiesse, F. and Fleisch, E. (2009). The emergence of counterfeit trade: a literature review. European Journal of Marketing, 43(3/4), pp. 320-349.

62. Steenkamp, J.-B. E. M. and Burgess, S. M. (2002). Optimum stimulation level and exploratory consumer behavior in an emerging consumer market. International Journal of Research in Marketing, 19(2), pp. 131150.

63. Swami, V., Chamorro-Premuzic, T., \& Furnhamd, A. (2009). Faking it: Personality and individual difference predictors of willingness to buy counterfeit goods. Journal of Socio-Economics, 38(5), pp. 820825 .

64. Tan, B. (2002) Understanding consumer ethical decision making with respect to purchase of pirated software. Journal of Consumer Marketing, 19(2), pp. 96-111.

65. Taylor, S. and Todd, P. (1995). Assessing IT usage: the role of prior experience. MIS Quarterly 19(4); 561570 .

66. Veloutsou, C. and Bian, X. (2008). A cross-national examination of consumer perceived risk in the context of non-deceptive counterfeit brands. Journal of Consumer Behaviour, 7(1), pp. 3-20.

67. Wee, C. H., S. J. Tan and Cheok, K. H. (1995). Non-price determinants of intention to purchase counterfeit goods, an exploratory study. International Marketing Review, 12(6), pp. $19-46$.

68. Wilcox, K., Kim, H. M. and Sen, S. (2009). Why Do Consumers Buy Counterfeit Luxury Brands. Journal of Marketing Research, 46(2), pp. 247-259.

69. Wood, W. (2000). Attitude Change: Persuasion and Social Influence. Annual Review of Psychology, 51, pp. 539-570. 


\section{NOTES}

